\title{
Spawning overlap of anchovy and sardine in the western North Pacific
}

\author{
Akinori Takasuka*, Hiroshi Kubota, Yoshioki Oozeki \\ National Research Institute of Fisheries Science, Fisheries Research Agency, 2-12-4 Fukuura, Kanazawa, Yokohama, \\ Kanagawa 236-8648, Japan
}

\begin{abstract}
Spatial and temporal spawning overlaps in Japanese anchovy Engraulis japonicus and sardine Sardinops melanostictus were examined using a long-term data set (1978 to 2004) of monthly egg and larval surveys (total of 102613 vertical tow samples) off the Pacific coast of Japan. Egg abundance was estimated in 15' latitude $\times 15^{\prime}$ longitude squares, and spawning area was calculated by summing areas of squares positive for egg occurrence. Both species had offshore expansion (inshore contraction) of spawning grounds with protracted (shortened) spawning periods during high- (low-) biomass phases. Although anchovy and sardine had different peak spawning periods (April to July and February to March, respectively), their spawnings were coincident from February to June in coastal waters. For anchovy, annual overlapping spawning area percentages of total spawning area and egg abundances in overlapping areas as percentages of total egg abundances were consistently low (6.4 to $30.6 \%$ and 7.2 to $39.9 \%$, respectively). In contrast, for sardine these percentages were consistently high and notably increased as population size decreased (21.1 to $80.8 \%$ and 1.4 to $86.9 \%$, respectively). Averaged over 5 yr (2000 to 2004), 68.5\% of the total area of sardine spawning grounds overlapped with anchovy spawning grounds, and $61.8 \%$ of annual sardine egg abundance was produced in spawning grounds that overlapped with anchovy. Thus, Japanese sardine population recovery is likely more difficult than Japanese anchovy population recovery (when interspecific interavtions occur).
\end{abstract}

KEY WORDS: Anchovy and sardine alternation $\cdot$ Spawning area $\cdot$ Egg abundance $\cdot$ Western North Pacific · Spatial and temporal overlap · Interspecific interaction · Egg and larval survey

Resale or republication not permitted without written consent of the publisher

\section{INTRODUCTION}

Despite the broadness of the ocean, favorable habitats for fish are limited by physical and biological conditions. If different fish species spawn simultaneously, their offspring may interact with one another. Such interspecific relationships might lead to intricate patterns of population dynamics that should be considered in fishery management (Botsford et al. 1997).

Anchovy Engraulis spp. and sardine Sardinops spp. are small pelagic fish that have exhibited out-of-phase population oscillations in several regions of the world (Lluch-Belda et al. 1989, Schwartzlose et al. 1999). Sardine are abundant when anchovy are relatively scarce, and vice versa; however, after a few decades, the dominant species abruptly alternates between anchovy and sardine. Landing histories indicated that oscillation patterns are roughly synchronous among panPacific regions and asynchronous between pan-Pacific regions and the Benguela region (Lluch-Belda et al. 1989, Schwartzlose et al. 1999, Chavez et al. 2003). Japanese sardine $S$. melanostictus populations virtually collapsed after their peak in the late 1980s, and, in turn, Japanese anchovy E. japonicus populations simultaneously increased (Fig. 1). In general, the sardine regime in the western North Pacific prevails when the sea surface is cooler and the anchovy regime prevails when the sea surface is warmer, in contrast to the eastern Pacific (Chavez et al. 2003). These anchovy and sardine alternations have been associated with the climate-induced ocean regime shifts (Lehodey et al. 2006). 


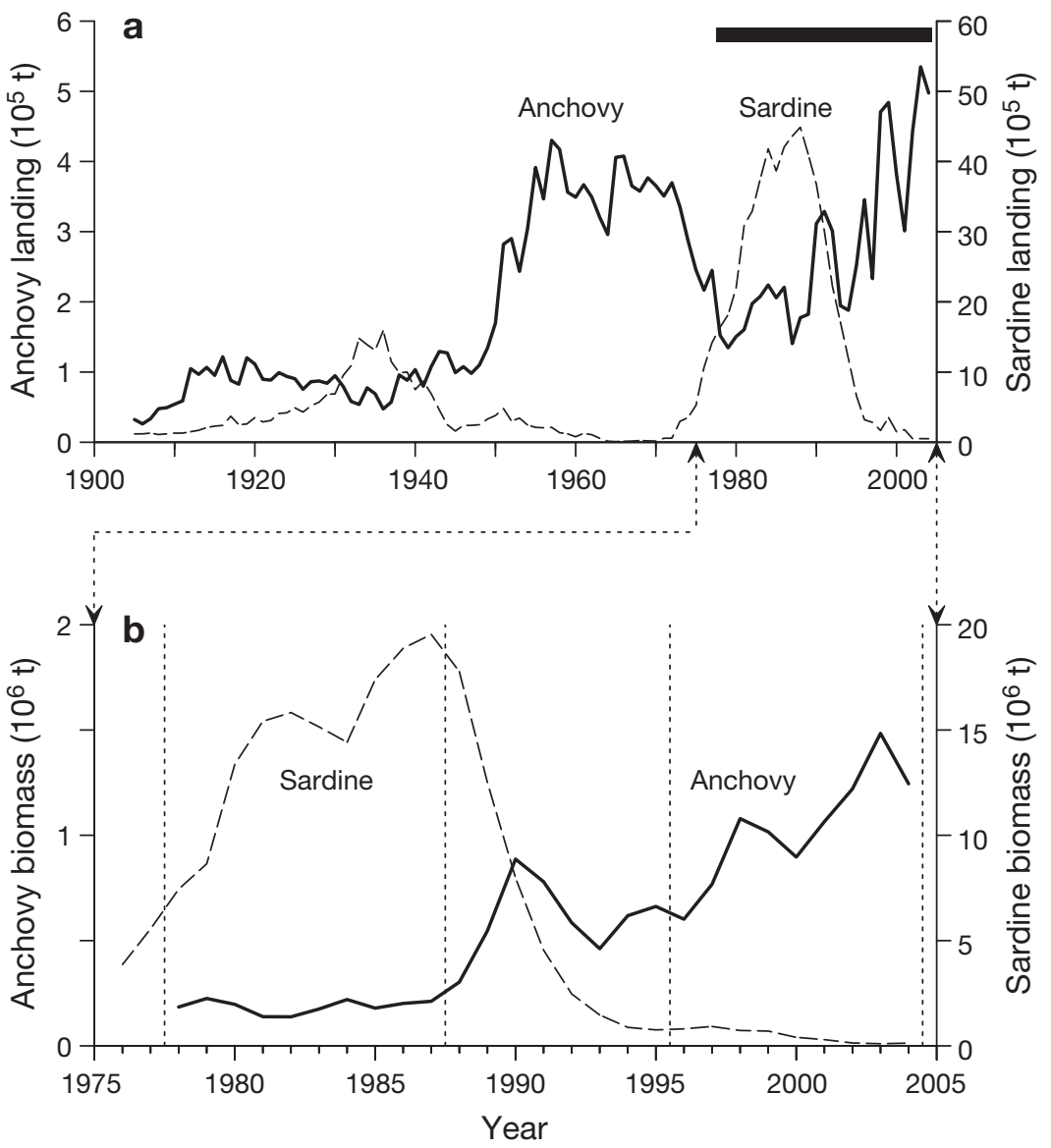

Fig. 1. Engraulis japonicus and Sardinops melanostictus. Out-of-phase oscillations in Japanese anchovy and sardine populations in the western North Pacific. (a) Total landing histories of anchovy and sardine in Japan. The landing data were updated from Yatsu et al. (2005). Horizontal bar indicates the period covered by the egg and larval survey data set (1978 to 2004). (b) Biomasses of the Pacific stocks of anchovy and sardine estimated through virtual population analyses (Nishida et al. 2005, Oozeki et al. 2005). The data set period is divided into 3 phases: (1) 1978-1987 (anchovy collapsed and sardine increasing), (2) 1988-1995 (anchovy increasing and sardine decreasing) and (3) 1996-2004 (anchovy increasing and sardine collapsed)

Many hypotheses have been proposed to explain the population dynamics of single species, in particular postulates based on multi-step processes through food webs (i.e. 'bottom-up' and 'top-down' controls). However, biological processes linking climate changes to multi-species alternations are controversial. The 'optimal growth temperature' hypothesis (Takasuka \& Aoki 2006, Takasuka et al. 2007) focuses on differential optimal growth rate temperatures during early life stages of Japanese anchovy $\left(22.0^{\circ} \mathrm{C}\right)$ and sardine $\left(16.2^{\circ} \mathrm{C}\right)$. This theory simply posits that temperature shifts between these optima lead to shifts between the 'warm' anchovy and 'cool' sardine regimes in the western North Pacific, providing a potential explanation of why one species flourishes and the couterpart species col- lapses under the same ocean regime. By comparing spawning temperature optima among species, the idea was then extended to multi-species regime shifts of anchovy, sardine, mackerel Scomber japonicus and $S$. australasicus and jack mackerel Trachurus japonicus in the western North Pacific (Takasuka et al. 2008a) and synchronous anchovy and sardine alternations on opposite sides of the North Pacific (Takasuka et al. 2008b). However, no single factor or mechanism appears sufficient to fully explain observed population dynamics. In fact, the temperature-based hypothesis failed to explain why Japanese sardine populations have not yet shown any sign of recovery, despite relatively favorable temperature conditions in recent years; multiple factors may synergistically exert effects on the anchovy and sardine alternations (Takasuka et al. 2007).

A prevailing controversial issue is the role of fishing mortality in the nonrecovery of sardine populations. Fishing impacts are now being assessed through simulation studies by several groups (e.g. Katsukawa 2007). Another possible impact limiting the recovery of populations is interspecific interaction between fish species; this factor has not been given detailed consideration. Different species might indirectly interact with one another, even if they are separated spatially and temporally. However, overlapping distributions will allow the most direct forms of interaction. A simple example is food competition among species with similar prey. Furthermore, less abundant species in multi-species schools (Bakun \& Cury 1999) and rare species in fish communities under predation pressure (Almany \& Webster 2004) may be at a disadvantage. Spawning overlaps may lead to such interspecific interactions during early life stages; identification of these overlaps will further a better understanding of biological mechanisms operating in multi-species population dynamics.

When, where and to what extent do anchovy and sardine spawnings co-occur? We examined spatial and temporal overlaps of Japanese anchovy and sardine spawnings using a long-term (1978 to 2004) egg and larval survey data set for the Pacific coast of Japan. Spawning areas and egg abundances of anchovy and sardine were estimated at a finer scale than in past studies with a focus on overlaps of egg occurence. 


\section{MATERIALS AND METHODS}

Egg survey data set. Extensive monthly egg and larval surveys have been conducted by 18 prefectural experimental stations or fisheries research institutes from Kagoshima (southernmost) to Aomori (northernmost) prefectures and 2 national research institutes of Fisheries Research Agency (National Research Institute of Fisheries Science and Seikai National Fisheries Research Institute) off the Pacific coast of Japan since 1978. The survey area covers the major spawning grounds of Japanese anchovy and sardine off the Pacific coast (Fig. 2). In the surveys, conical or cylindricalconical plankton nets with mouth ring diameters of 45 or $60 \mathrm{~cm}$ and mesh sizes of 0.33 or $0.335 \mathrm{~mm}$ were towed vertically from $150 \mathrm{~m}$ depth (if the depth was $<150 \mathrm{~m}$, nets were lowered to just above the bottom). Other oceanographic observations, such as sea surface temperature (SST) measurements, were made. The plankton net was equipped with a flow-meter to estimate egg density. The depth range towed by the nets covered the vertical distribution ranges of anchovy and sardine eggs.

The monthly surveys were conducted year-round, with an approximately consistent sampling effort, although surveys tended to be slightly more intensive during early spring (Fig. 3a). Mean sampling area coverage (sums of areas of $15^{\prime}$ latitude $\times 15^{\prime}$ longitude squares in which sampling was conducted) and number of samples (frequency of plankton net tows) per month during 1978 to 2004 ranged from $7.05 \times 10^{4} \mathrm{~km}^{2}$ (September) to $14.58 \times 10^{4} \mathrm{~km}^{2}$ (February) and from 253 (September) to 456 (February), respectively. Annual total sampling area coverage and number of samples (summed for all months) have been almost constant since 1978 , ranging from $92.50 \times 10^{4} \mathrm{~km}^{2}$ (1978) to

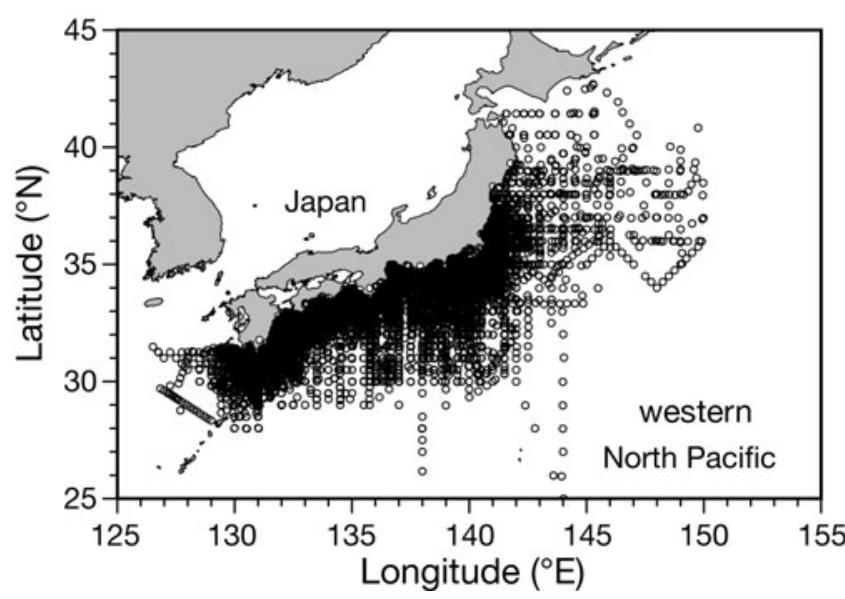

Fig. 2. Egg and larval survey sampling stations off the Pacific coast of Japan from 1978 to 2004. Both fixed and unfixed stations are shown ( $\mathrm{n}=102613$ samples)

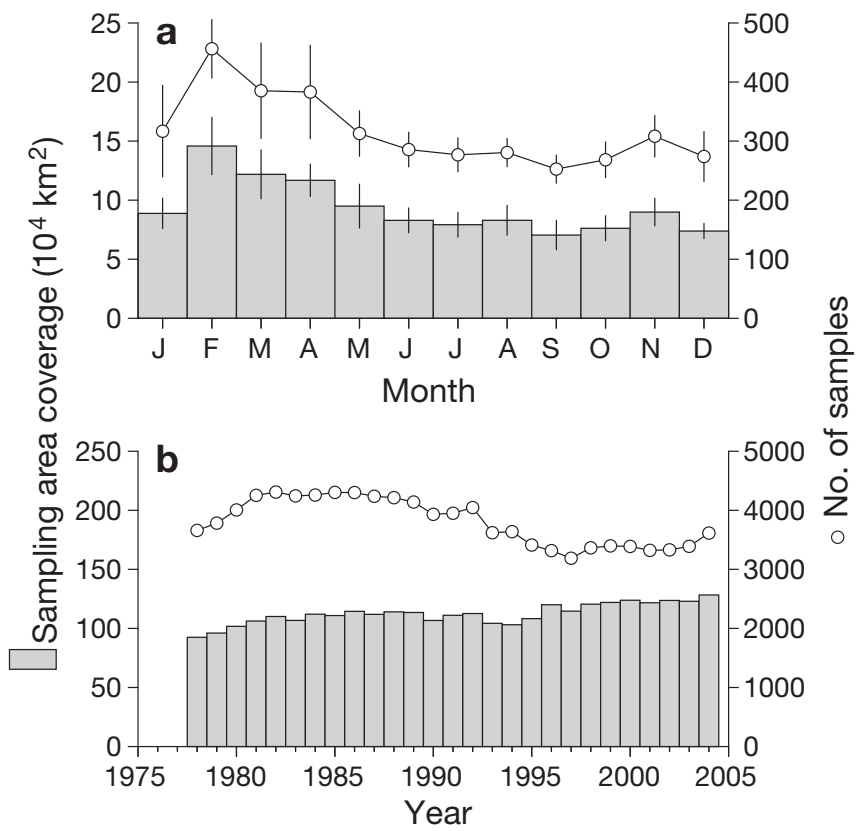

Fig. 3. Egg and larval surveys: sampling area coverage and sample sizes off the Pacific coast of Japan from 1978 to 2004. (a) Mean sampling area coverage and number of samples for each month. Means \pm SD. (b) Annual total sampling area coverage and number of samples for each year

$128.31 \times 10^{4} \mathrm{~km}^{2}(2004)$ and from 3188 (1997) to 4308 (1982), respectively (Fig. 3b). The net samples were identified, sorted, and Japanese anchovy and sardine eggs were counted. The data set has been updated for the period of 1978 to 2004 and comprises a total of 102613 samples (tows) in the present analyses.

Egg abundance. Monthly egg abundance was calculated for anchovy and sardine in $15^{\prime}$ latitude $\times 15^{\prime}$ longitude squares. This square resolution was updated by Oozeki et al. (2007) from a resolution of 30' latitude $\times$ $30^{\prime}$ longitude used in previous survey reports (e.g. Mori et al. 1988) and published papers (Watanabe et al. 1996, 1997, Zenitani \& Kimura 1997). Our calculation procedures were similar to those adopted in past reports and papers except for the square resolution. First, the number of eggs was standardized by flowmeter revolution (filtering rate), towing distance, and tow cable angle to estimate egg density (number per $\mathrm{m}^{2}$ ) in the water column for each tow, although a portion of the tows lacked necessary data for standardization. Egg density $\left(\mathrm{m}^{-2}\right)$ in the water column was calculated for each $15^{\prime}$ latitude $\times 15^{\prime}$ longitude square by averaging arithmetically the egg densities of all tows conducted in the square for each month. Egg abundance in the $15^{\prime} \times 15^{\prime}$ square $i$ in month $j\left(E_{i j}\right)$ was calculated using the egg density $\left(\mathrm{m}^{-2}\right)$ in the square in that month $\left(D_{i j}\right)$, with egg incubation time and survival rate being considered (Nakai \& Hattori 1962): 


$$
E_{i j}=\frac{1}{S} \cdot \frac{d_{j}}{d^{\prime}{ }_{i j}} \cdot A_{i} \cdot D_{i j}
$$

where $s$ is the survival rate during the egg stage, which was estimated as 0.600 for anchovy and 0.571 for sardine (Watanabe 1983, Mori et al. 1988), $d_{j}$ is the number of days in month $j, d_{i j}^{\prime}$ is the egg incubation time in days in the sampling square $i$ in month $j_{\text {, and }} A_{j}$ is the area of the square $i\left(\mathrm{~m}^{2}\right)$. The egg incubation time was estimated using a function of SST based on the Arrhenius equation (Hattori 1983, Watanabe 1983).

$$
d_{i j}^{\prime}=\frac{1}{24} \cdot \frac{1}{a} \cdot \exp \left(\frac{b}{T_{i j}+273}\right)
$$

where $T_{i j}$ is the mean SST weighted by egg occurrence, $a$ and $b$ are constants $\left(a=1.585 \times 10^{12}, b=9.348 \times 10^{3}\right.$ for anchovy and $a=3.981 \times 10^{14}, b=10.96 \times 10^{3}$ for sardine). The egg survival rates were estimated based on the data set providing the number of eggs for 3 developmental stages, assuming survival is a monotonically decreasing exponential function of days after spawning (Watanabe 1983, Mori et al. 1988). Survival rate also varies with environmental factors (e.g. SST), but was fixed at a constant value because of data limitations. In order to realistically assess the quantitative data, egg incubation time and survival rate were used to estimate the monthly initial abundances of eggs spawned rather than snapshot data. The number of larvae captured was also available in the data set, but larval abundances were not estimated because of the lack of reliable data on mortality rates, increased biases (compared to egg analysis) due to transport by currents and probability of net avoidance by larger larvae.

Spawning overlap status. Each square with anchovy and/or sardine eggs was assigned to at least 1 of 5 categories for each species by the occurrence of eggs and the extent of overlap with the counterpart species. For anchovy, the categories were defined, as follows. 'A-positive': anchovy eggs occurred; 'AS-positive': anchovy eggs co-occurred with sardine eggs; 'S-dominated': anchovy eggs were less abundant than sardine eggs (i.e. sardine-dominated square for anchovy); 'Sdominated-2': anchovy eggs were less than a half of the abundance of sardine eggs; 'S-dominated-10': anchovy eggs were less than a tenth of the abundance of sardine eggs. Higher categories (e.g. AS-positive) included the squares of lower categories (S-dominated, S-dominated-2 and S-dominated-10), i.e. the squares assigned to lower categories (e.g. S-dominated) were also assigned to higher categories (A-positive and ASpositive). Similarly, for sardine the categories were defined as 'S-positive' (sardine eggs occurred), 'SApositive' (= AS-positive; sardine eggs co-occurred with anchovy eggs), 'A-dominated', 'A-dominated-2' and 'A-dominated-10' (sardine is the minor species in the anchovy-dominated square). For example, for a square in which anchovy egg abundance was less than a half but more than a tenth of sardine egg abundance, the categories to which this square was assigned were A-positive, AS-positive, S-dominated and S-dominated-2 for anchovy and S-positive and SA-positive for sardine.

Anchocy and sardine spawning areas and egg abundances were calculated for the 5 categories to examine the extent of the overlap between the species. The entire area of spawning grounds and total egg abundance of anchovy (sardine) in a given month were calculated by summing up the areas of squares assigned to A- (S-) positive and the egg abundances in the A- (S-) positive areas, respectively, for each month. The sum of areas of squares assigned to ASpositive (= SA-positive) corresponded to the overlapped spawning grounds of anchovy and sardine; the sum of anchovy (sardine) egg abundances in the 'AS(SA-) positive' areas was regarded as the portion of anchovy (sardine) eggs that overlapped with sardine (anchovy) eggs. Similarly, the sum of anchovy (sardine) egg abundances in the S- (A-) dominated areas was regarded as the portion of anchovy (sardine) eggs spawned in the common spawning grounds dominated by sardine (anchovy) eggs.

Seasonal changes in spawning area and egg abundance were examined by averaging the monthly data for the entire period and several phases of population dynamics. To describe the decadal shifts, total spawning area and egg abundance in a given year were calculated by simply summing the monthly data from January to December of a year for anchovy and from October of the previous year to September in the following year for sardine (based on the respective spawning seasons, see Results). These spatial and temporal variations of spawning grounds and egg abundances were compared between anchovy and sardine, with a focus on the extent of overlap. Finally, the relationships between the extent of spawning overlap and the population levels were examined. As an indicator of the population level, we used the annual spawning stock biomass percentages of maximum spawning stock biomass for each species (estimated through virtual population analyses, Nishida et al. 2005, Oozeki et al. 2005). An exponential function was fitted to the plot of overlapped spawning area percentage of annual total spawning area against the population level indicator for anchovy AS-positive and S-dominated and sardine SA-positive and A-dominated. Similarly an exponential function was fitted to the egg abundance percentages (in the overlapped spawning area) of annual total egg abundances. An analysis of covariance (ANCOVA) was applied to test for any differences in the linear regressions of (1) ln-transformed 
overlapped spawning area percentages of total area (dependent variable) against ln-transformed population level indicators (independent variable) between anchovy and sardine in the same category level (e.g. anchovy S-dominated versus sardine A-dominated), and (2) ln-tranformed egg abundances in overlapped areas as percentages of total abundance (dependent variable) against ln-transformed population level indicators (independent variable) between anchovy and sardine in the same category level (e.g. anchovy Sdominated versus sardine A-dominated).

\section{RESULTS}

\section{Spatial changes}

Anchovy and sardine had offshore expansions of spawning grounds with protracted spawning periods during the high-biomass phases, and, in turn, they had inshore contractions of spawning grounds with shortened spawning periods during the low-biomass phases. Spatial dynamics of egg distributions from February to June are plotted for 1988 (Fig. 4a) and 2004 (Fig. 4b) as representative years during the sardine and anchovy regimes, respectively. In 1988, anchovy had active spawning in inshore waters only around Kyushu, Sagami Bay and Kashima nada in March, around Kyushu to Tohoku in April and May, and around Tosa Bay to Kashima nada in June. In 2004, however, anchovy spawned more intensively and widely around Kyushu to Tohoku from February to June, and the spawning grounds expanded to offshore waters from April to June. In contrast, in 1988, sardine spawned actively around Kyushu to Kashima nada from February to April and the spawning grounds were located from inshore to offshore waters; in 2004 the main spawning grounds of sardine were in inshore waters only around Tosa Bay and Sagami Bay in February and March and sporadically around Sagami Bay and Kashima nada in later months. In both years, common spawning grounds were formed in coastal areas, where anchovy and sardine egg occurrences overlapped. Such patterns were similar in contiguous years during the same phases of population dynamics (data not shown).

\section{Seasonal changes}

Spawning peaks clearly differed between anchovy and sardine; however, the spawnings overlapped from late winter to early summer in data averaged for the period from 1978 to 2004. Anchovy spawned throughout the year, with a spawning area peak from April to
July, while sardine spawned mainly from October to July with a spawning area peak from February to April (Fig. 5). Anchovy and sardine spawning areas overlapped mainly from January to July. The peaks of egg abundances were more distinct and tended to occur in later months for anchovy and in earlier months for sardine relative to the peaks of spawning areas: anchovy had a peak in egg abundance from May to July, while sardine had a peak in egg abundance from February to March (Fig. 6). For sardine, the extent of the overlap with anchovy appeared to be greater in later months of the spawning periods.

The scale of the spawning area at the spawning peaks did not differ greatly between anchovy and sardine; the maximum mean spawning area was $4.61 \times$ $10^{4} \mathrm{~km}^{2}$ in May for anchovy and $3.97 \times 10^{4} \mathrm{~km}^{2}$ in February for sardine. There was no significant difference in spawning areas between anchovy in May and sardine in February (Mann-Whitney U test, $p=0.223$ ). However, the mean egg abundance maximum of anchovy $\left(616 \times 10^{12}\right.$ in June) was approximately double that of sardine $\left(310 \times 10^{12}\right.$ in February $)$; there was a significant difference in egg abundance between anchovy in May and sardine in February (Mann-Whitney $\mathrm{U}$ test, $\mathrm{p}=0.016$ )

Seasonal patterns were described for different phases of population dynamics in terms of the spawning area (Fig. 5) and egg abundance (Fig. 6). The time period (Fig. 1a) was divided into 3 phases by the population dynamics patterns of anchovy and sardine (Fig. 1b): 1978-1987 (anchovy collapsed and sardine increasing), 1988-1995 (anchovy increasing and sardine decreasing) and 1996-2004 (anchovy increasing and sardine collapsed). For both spawning area and egg abundance, there were differences among phases in spawning season, spawning peak and the extent of the overlap with the counterpart species. For example, anchovy active spawning started earlier during the phases 1988-1995 and 1996-2004 than during the phase 1978-1987. Sardine spawning peaks tended to be delayed during the phase 1996-2004 relative to the other 2 phases. The extent of overlap with the counterpart species decreased slightly for anchovy and increased dramatically for sardine through the shift from the 1978-1987 phase to the 1988-1995 and 1996-2004 phases.

\section{Decadal changes}

Decadal changes in spawning areas (Fig. 7) and egg abundances (Fig. 8) reflected anchovy spawning ground offshore expansion from the late 1980s, and sardine spawing ground offshore expansion until the late 1980s and subsequent inshore contraction. Anchovy 


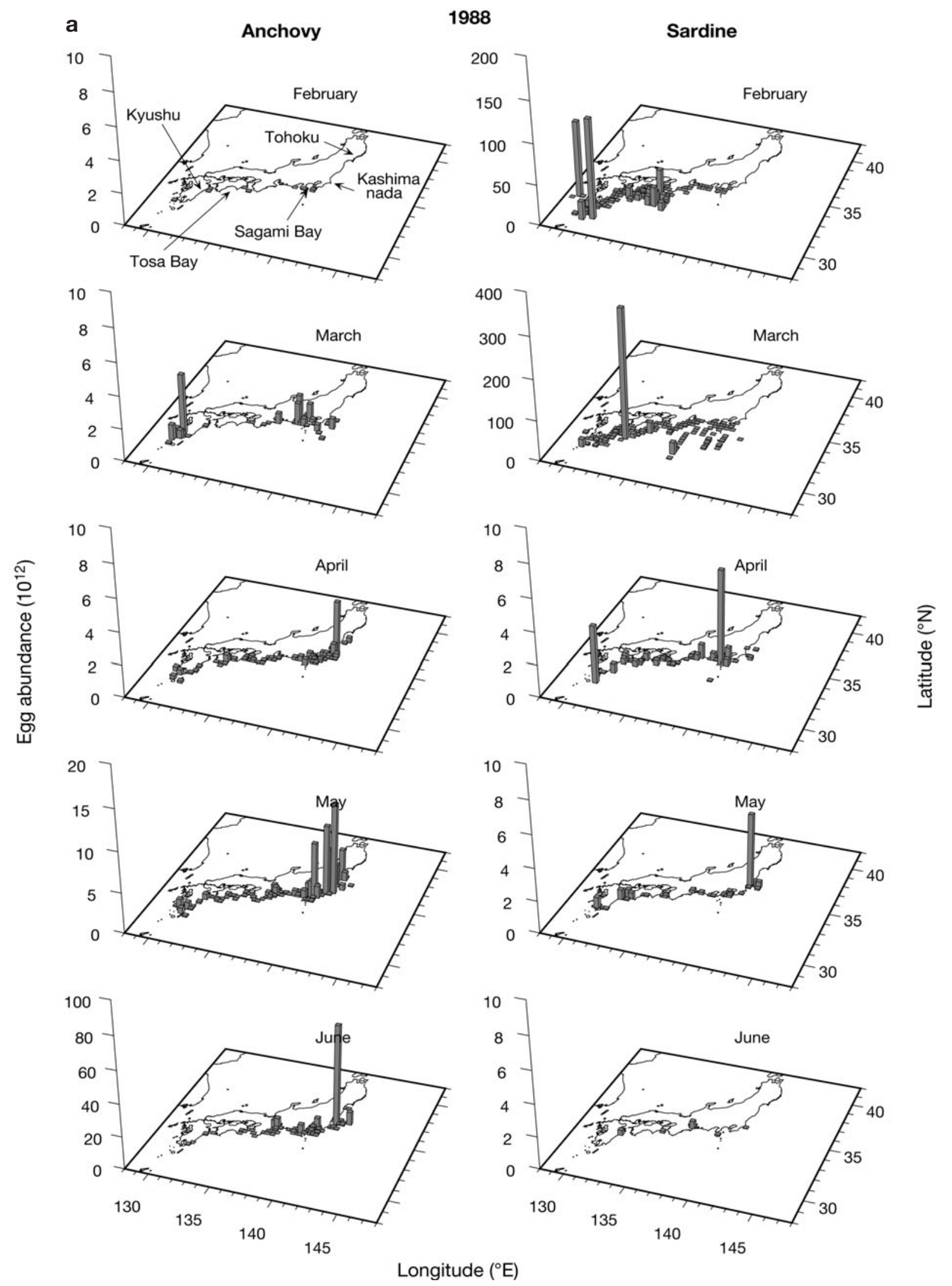

Fig. 4. Engraulis japonicus and Sardinops melanostictus. Examples of Japanese anchovy and sardine monthly egg abundance distributions in the western North Pacific. (a) February to June, 1988 during the sardine regime. (b) February to June, 2004 during the anchovy regime. Note different $z$-axis scales 


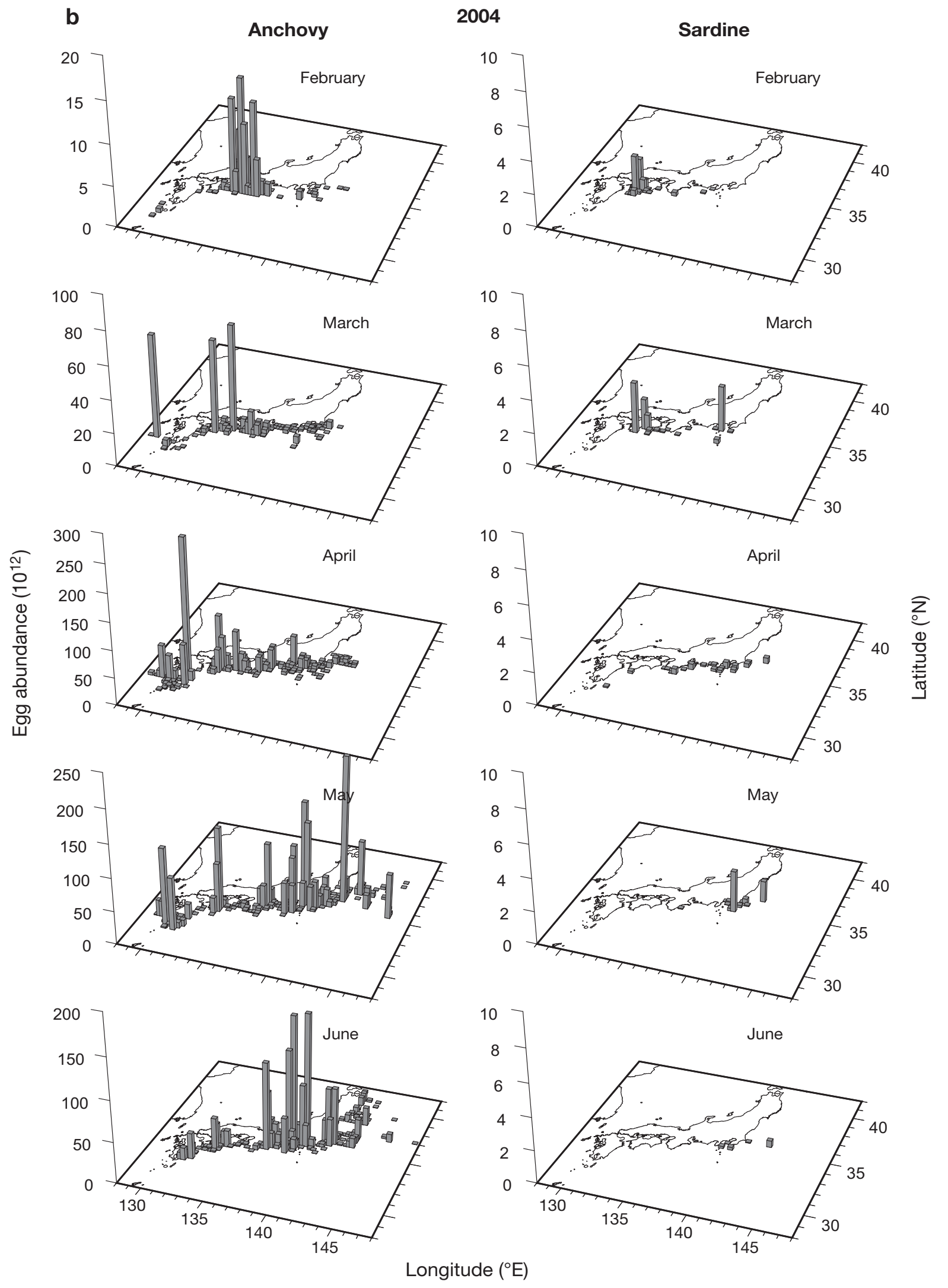

Fig. 4 (continued) 

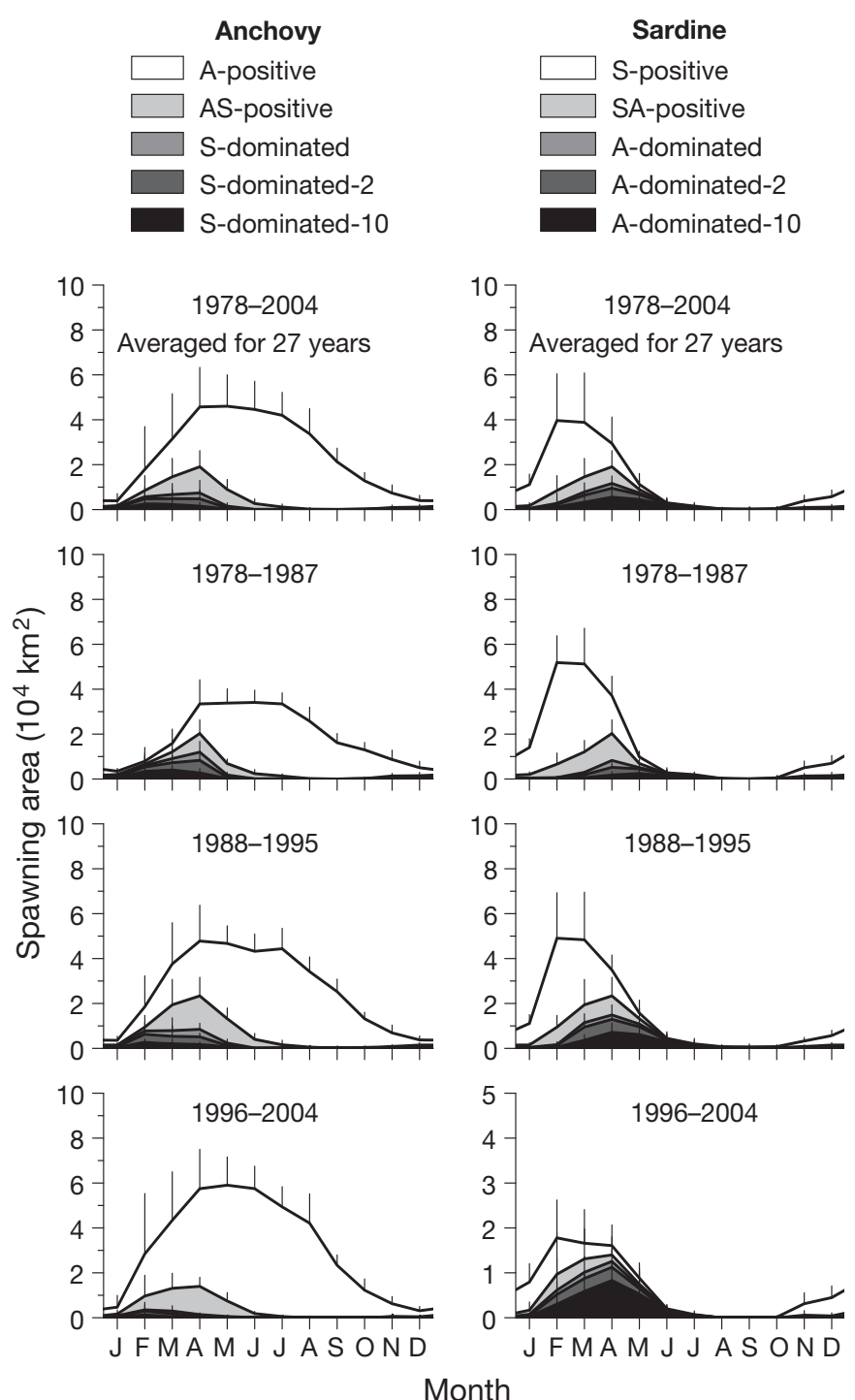

Fig. 5. Engraulis japonicus and Sardinops melanostictus. Seasonal changes in the spawning areas of Japanese anchovy and sardine showing their overlaps in the western North Pacific from 1978 to 2004. A-positive (S-positive): anchovy (sardine) eggs occurred; AS-positive (SA-positive): anchovy (sardine) eggs co-occurred with sardine (anchovy) eggs; S-dominated (A-dominated): anchovy (sardine) eggs were less abundant than sardine (anchovy) eggs; S-dominated-2 (A-dominated-2): anchovy (sardine) egg abundances were $<1 / 2$ sardine (anchovy) egg abundances; S-dominated-10 (A-dominated-10): anchovy (sardine) egg abundances were $<1 / 10$ sardine (anchovy) egg abundances. Means + SD for the period 1978 to 2004 and for the 3 phases (1978-1987, 1988-1995 and 1996-2004). Figures are shown as overlaid images: i.e. AS-positive area is a portion of the A-positive area. See text for details

spawning area and egg abundance started to increase in the late $1980 \mathrm{~s}$, with some fluctuations. In contrast, sardine spawning area and egg abundance declined markedly from the late 1980s and the early 1990s, respectively, until recently. The anchovy spawning

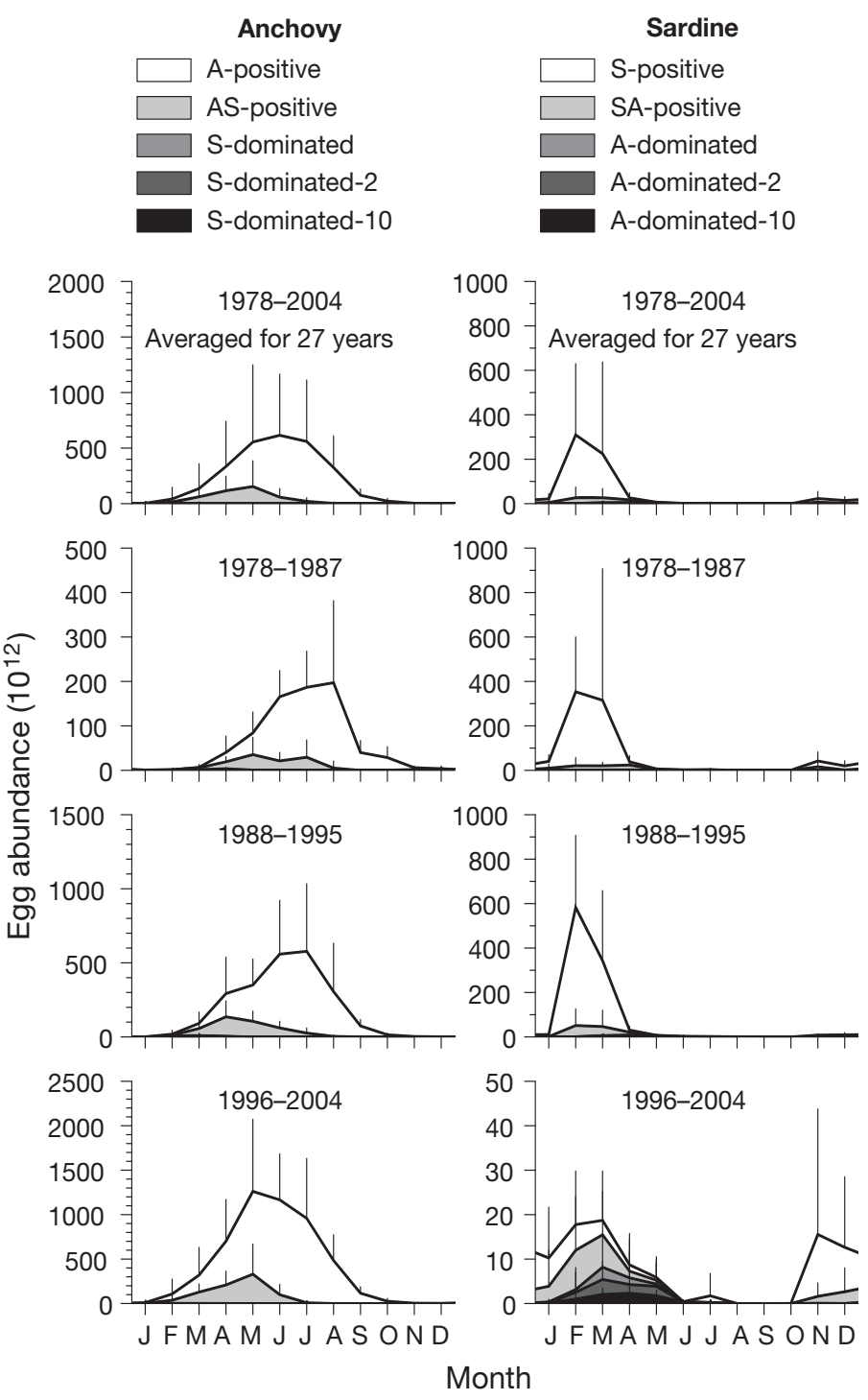

Fig. 6. Engraulis japonicus and Sardinops melanostictus. Seasonal changes in Japanese anchovy and sardine egg abundances showing their overlaps in the western North Pacific from 1978 to 2004. See Fig. 5 legend and text for definitions of overlap status categories. Means $+\mathrm{SD}$ for the period of 1978 to 2004 and 3 phases $(1978-1987,1988-1995$ and 1996-2004). Figures are shown as overlaid images

areas summed by year ranged from $16.64 \times 10^{4} \mathrm{~km}^{2}$ in 1978 to $55.92 \times 10^{4} \mathrm{~km}^{2}$ in 1999 ; the sardine spawning areas summed by year ranged from $3.04 \times 10^{4} \mathrm{~km}^{2}$ in 2002 to $23.63 \times 10^{4} \mathrm{~km}^{2}$ in 1990 . Anchovy annual egg abundances ranged from $361 \times 10^{12}$ in 1978 to $8604 \times$ $10^{12}$ in 1999; sardine annual egg abundances ranged from $18 \times 10^{12}$ in 2002 to $2998 \times 10^{12}$ in 1986 .

The extent of spawning overlaps with the counterpart species differed markedly between anchovy and sardine. For anchovy, overlapping spawning area percentages of total area, and egg abundance percentages 


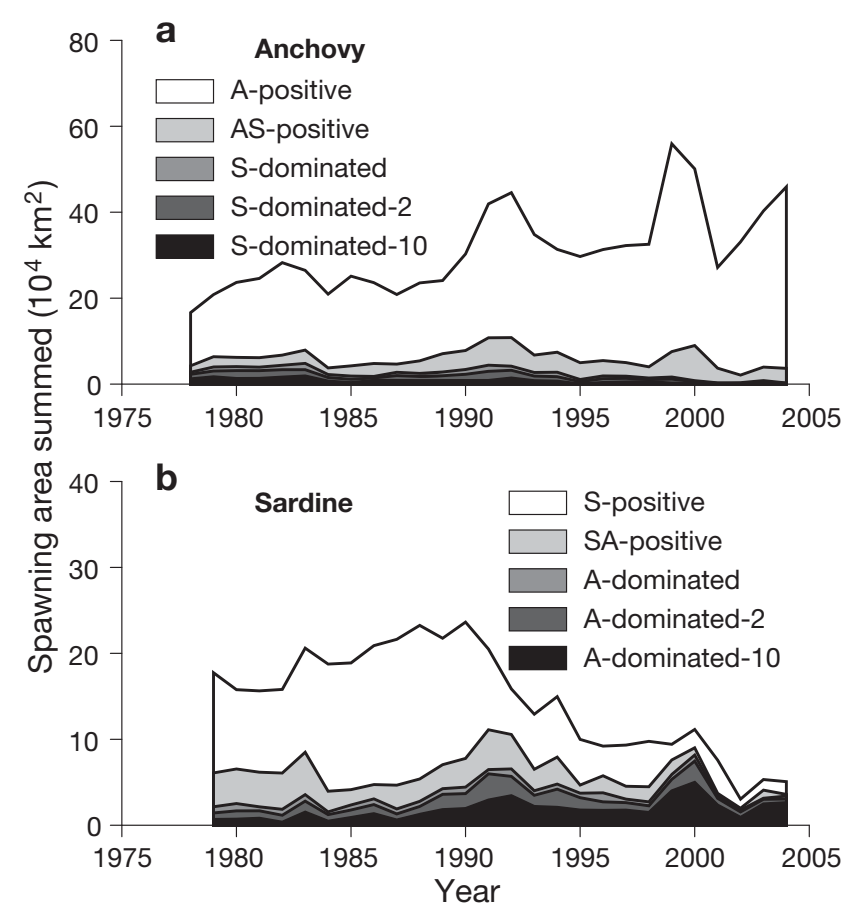

Fig. 7. Engraulis japonicus and Sardinops melanostictus. Decadal shifts in annual total spawning areas of Japanese (a) anchovy and (b) sardine showing their overlaps in the western North Pacific from 1978 to 2004. See Fig. 5 legend and text for definitions of overlap status categories. Areas under curves are overlain

in overlapping areas of total egg abundance were consistently low, ranging from 6.4 to $30.6 \%$ and 7.2 to $39.9 \%$, respectively. The percentages of anchovy spawning areas dominated by sardine fluctuated in the ranges of 0.5 to $19.2 \%, 0.3$ to $14.7 \%$ and 0.0 to $8.2 \%$ for S-dominated, S-dominated-2 and S-dominated-10, respectively; the percentages of anchovy egg abundances in the sardine-dominated spawning areas fluctuated in the range of 0.02 to $3.9 \%, 0.003$ to $2.2 \%$ and 0.0 to $1.3 \%$ for S-dominated, S-dominated-2 and Sdominated-10, respectively. In contrast, for sardine, overlapping spawning area percentages of total area and egg abundance percentages in overlapping areas of total egg abundance were relatively high, ranging from 21.1 to $80.8 \%$ and 1.4 to $86.9 \%$, respectively. The percentages of the sardine spawning areas dominated by anchovy fluctuated in the ranges of 8.3 to $73.3 \%, 6.1$ to $66.9 \%$ and 2.3 to $52.1 \%$ for A-dominated, A-dominated-2 and A-dominated-10, respectively; the percentages of sardine egg abundances in the anchovydominated spawning areas fluctuated in the range of 0.4 to $81.5 \%, 0.3$ to $73.1 \%$ and 0.1 to $22.3 \%$ for A-dominated, A-dominated-2 and A-dominated-10, respectively. Averaged over 5 yr (2000 to 2004) during the anchovy regime, $68.5 \%$ of the total area of the sardine spawning grounds overlapped with anchovy spawning

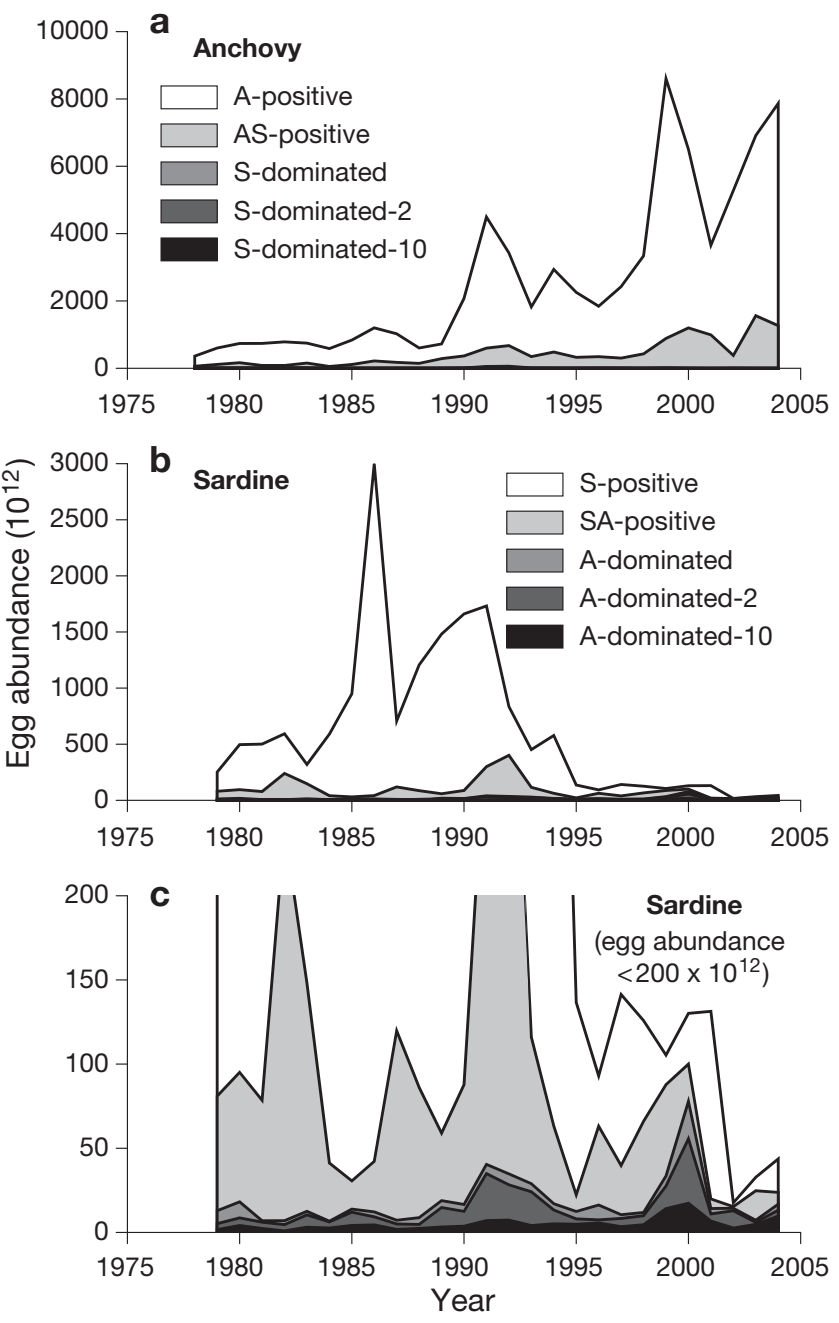

Fig. 8. Engraulis japonicus and Sardinops melanostictus. Decadal shifts in annual total egg abundances of Japanese (a) anchovy and (b) sardine showing their overlaps in the western North Pacific from 1978 to 2004. (c) Closeup of (b) (sardine) for the range of egg abundance $<200 \times 10^{12}$. See Fig. 5 legend and text for definitions of overlap status categories. Areas under curves are overlain

grounds and $60.5 \%$ corresponded to anchovy-dominated spawning grounds. Similarly, $61.8 \%$ of annual sardine egg abundance occurred in overlapping spawning grounds and $42.6 \%$ occurred in anchovydominated spawning grounds.

The extent of the overlap with the counterpart species by population level also revealed different patterns between anchovy and sardine (Fig. 9). Overall, the extent of overlaps (when standardized by population level and compared within the same level of category, e.g. anchovy S-dominated versus sardine A-dominated) was higher for sardine than for anchovy. Percentages of overlapped spawning areas and egg abundance in the overlapped areas to the total area 

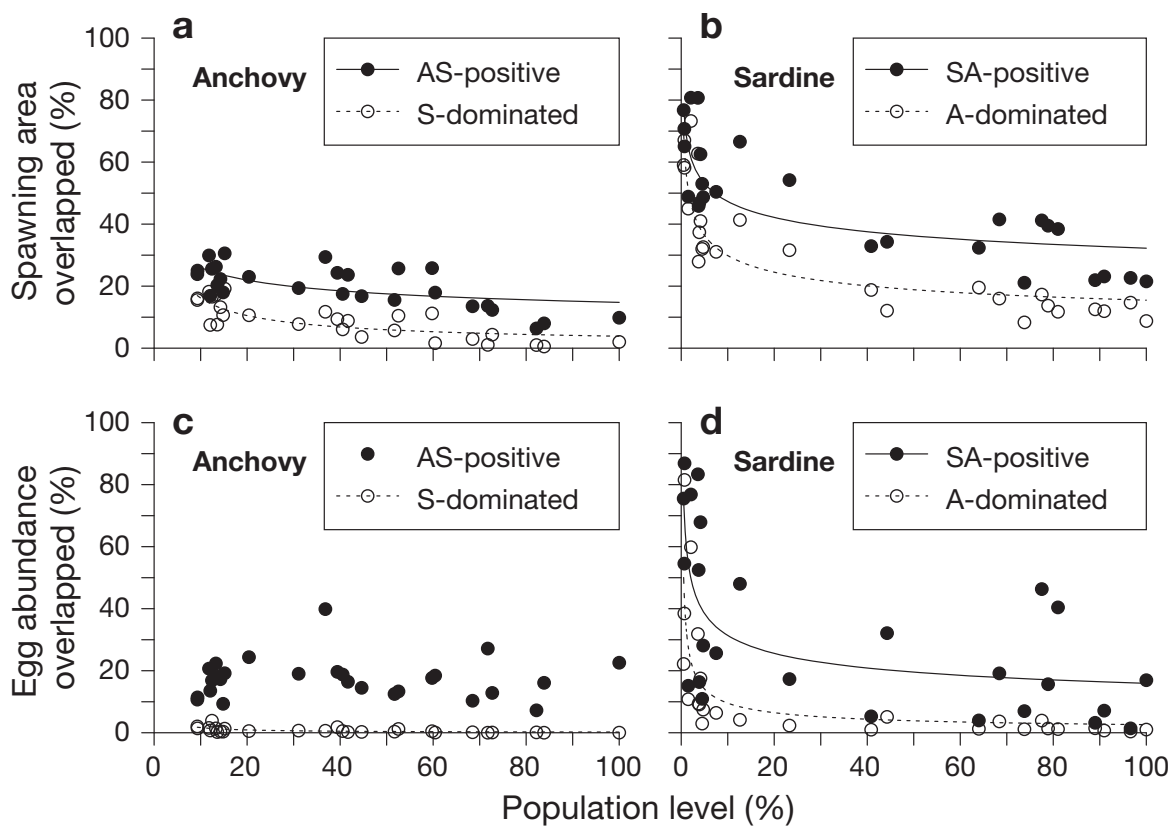

Fig. 9. Engraulis japonicus and Sardinops melanostictus. Relationships between population level and extent of spawning overlaps with the counterpart species for Japanese anchovy and sardine in the western North Pacific from 1978 to 2004. $(a, b)$ Overlapped spawning area percentage of annual total spawning area plotted against annual spawning stock biomass percentage of maximum spawning stock biomass. (c,d) Overlapped spawning area egg abundance percentage of annual total egg abundance plotted against annual spawning stock -biomass percentage of maximum spawning stock biomass. See Table 1 for regression summary statistics. See Fig. 5 legend and text for definitions of overlap status categories and abundance were monotonically decreasing exponential functions of the population level indicator except for anchovy AS-positive egg abundance (Table 1, Fig. 9). The intercepts of linear regressions of ln-transformed data differed between anchovy ASpositive and sardine SA-positive in spawning area (ANCOVA, $F=62.87$, df $=1, \mathrm{p}<0.001$ ), and the slopes of the linear regressions differed between anchovy Sdominated and sardine A-dominated in spawning area and between anchovy S-dominated and sardine A- dominated in egg abundance $(\mathrm{p}<0.001)$, although the regression itself was not significant for anchovy ASpositive in egg abundance $(p=0.944)$. For sardine, the percentages of overlapped spawning areas and egg abundances in such areas to the total area and abundance increased notably as population sizes decreased; such patterns were not observed or were very weak for anchovy. In other words, the anchovy population level (down to $9.3 \%$ ) did not decline as much as the sardine population level (down to $0.5 \%$ ).
Table 1. Engraulis japonicus and Sardinops melanostictus. Summary statistics for relationships between population level and extent of spawning overlaps with the counterpart species for Japanese anchovy and sardine in the western North Pacific from 1978 to 2004. Category of spawning area: regressions of overlapped spawning area percentage of annual total spawning area on annual spawning stock biomass percentage of maximum spawning stock biomass. Category of egg abundance: regressions of overlapped spawning area egg abundance percentage of annual total egg abundance on annual spawning stock biomass percentages of maximum spawning stock biomasses. See Fig. 9 for regression plots. See Fig. 5 legend and text for definitions of overlap status categories

\begin{tabular}{|lccrr|}
\hline Category & Regression & $\mathrm{n}$ & $\mathrm{r}^{2}$ & $\mathrm{p}$ \\
\hline Spawning area & & & & \\
Anchovy AS-positive & $y=45.77 x^{-0.246}$ & 27 & 0.372 & 0.001 \\
Anchovy S-dominated & $y=67.93 x^{-0.623}$ & 27 & 0.625 & $<0.001$ \\
Sardine SA-positive & $y=69.39 x^{-0.166}$ & 26 & 0.656 & $<0.001$ \\
Sardine A-dominated & $y=57.64 x^{-0.286}$ & 26 & 0.788 & $<0.001$ \\
Egg abundance & & & & \\
Anchovy AS-positive & Not significant & 27 & 0.002 & 0.826 \\
Anchovy S-dominated & $y=12.48 x^{-0.876}$ & 27 & 0.359 & 0.009 \\
Sardine SA-positive & $y=61.77 x^{-0.294}$ & 26 & 0.463 & $<0.001$ \\
Sardine A-dominated & $y=34.90 x^{-0.563}$ & 26 & 0.536 & 0.001 \\
\hline
\end{tabular}

\section{DISCUSSION}

We present several lines of evidence showing interspecific differences in spatial and temporal overlaps between Japanese anchovy and sardine spawnings in the western North Pacific. Anchovy and sardine had clearly different peaks and periods of spawning activity; however, their spawnings overlapped considerably both spatially and temporally. A marked difference lies in the extent of the overlaps: the percentages of the overlapped portion to the total were greater for sardine than for anchovy. The dynamics of overlaps and the differences between anchovy and sardine would be attributed to several key factors in the out-of-phase population oscillations, viz. spawning peak and period, expansion and contraction of spawning grounds and level of biomass fluctuations. The offshore 
expansion and inshore contraction of spawning grounds were consistent with the patterns previously reported (Watanabe et al. 1996, 1997, Zenitani \& Kimura 1997). Since the areas of coastal spawning grounds were relatively constant for anchovy and sardine, the out-of-phase oscillations of expansion and contraction would limit spawning overlaps to coastal areas. Despite the considerable spawning overlaps from February to June and the similar scales of spawning areas at the spawning peaks (as the anchovy spawning period extends throughout the year), lower percentages of overlapped anchovy spawning area and egg abundance to the totals occurred even during the sardine regime. In contrast, for sardine, the overlapped area and egg abundance account for a considerable portion of the total, because the sardine spawning period is rather limited to around the main season of overlap, and this phenomenon was particularly marked during sardine low-biomass phases. During the anchovy regime, the delayed spawning peak of sardine would have the synergistic effect of increasing overlap with anchovy whose spawning peak occurs earlier. The level of overlap ( $>60 \%$ ) for sardine was far greater than expected.

The overlap of egg occurrences may provide a necessary (but not sufficient) condition for direct interspecific interactions for resouces such as food during the early life stages. At the same time, the overlap also indicates the possibility of interspecific interactions of spawning adults in the overlapped spawning grounds. Assuming such interspecific interactions, the present study indicates that the spawning overlaps would be more critical for sardine than for anchovy in the western North Pacific. The extent of Japanese sardine population fluctuations was more than 10 times that of Japanese anchovy (Fig. 1). This marked difference has sometimes been interpreted as a scenario in which sardine have a run of alternations and anchovy merely fill the interstices when sardine populations collapse. However, our results point to an alternative hypothesis: anchovy are less subject to spatial and temporal overlaps with sardine and have interspecific interactions. Under this interpretation, sardine are potentially more susceptible to spawning ground overlap (with anchovy), particularly when population levels are low.

If this alternative hypothesis is correct, considerable overlaps have likely exerted negative impacts on sardine populations synergistically with fishing mortality during recent years, although relative contributions are still unknown. Unfortunately, the data set period (1978 to 2004) does not allow us to compare the recent recruitment conditions with those in the early 1970s when sardine populations recovered despite probable overlaps. However, even if the overlaps appear to be similar at larger scales, their influences might vary spatially and temporally. For example, the overlaps tended to occur in restricted locales such as Tosa Bay where spawning activities were highly concentrated. Accordingly, further long-term monitoring at fine scales is required. Also, future studies may need to consider possible effects of patchy distributions on egg abundance estimates. Acoustic surveys have shown that the spawners of Sardinops sagax are more patchily distributed than those of Engraulis capensis in the southern Benguela system (Barange \& Hampton 1997, Barange et al. 2005). Similarly, such fine scale analyses of species-specific spatial structures may provide insight into the selection of an appropriate spatial scale (resolution) or tool of analysis (square or smoothing) (although at present this is difficult to determine for our data set) and, thus, might also enhance the accuracy of spawning grounds spatial analyses in the western North Pacific.

Spawning habitat dynamics in the western North Pacific have been reported for anchovy (Zenitani \& Kimura 1997, Oozeki et al. 2007) and sardine (Watanabe et al. 1996, 1997, Oozeki et al. 2007). Previously, anchovy and sardine tended to be analyzed separately in this region, yet a uniform approach for both species would allow their relationships to be analyzed in a more comprehensive manner (e.g. Nakata et al. 2000, Oozeki et al. 2007, present study). In other ocean systems, spatial and temporal dynamics of spawning habitats and distributions of eggs and adults have been examined for co-occurring anchovy and sardine either concurrently or separately: Engraulis mordax and Sardinops sagax in the California Current system (Lluch-Belda et al. 1991, Smith et al. 2001, RodríguezSánchez et al. 2002, Curtis 2004), E. ringens and S. sagax in the Humboldt Current system (Gutiérrez et al. 2007), E. capensis and S. sagax in the southern Benguela system (Barange \& Hampton 1997, Barange et al. 2005, Twatwa et al. 2005), E. encrasicolus and Sardina pilchardus in the Bay of Biscay (Bellier et al. 2007, Planque et al. 2007) and the eastern Mediterranean Sea (Giannoulaki et al. 2006), E. australis and S. sagax in South Australian waters (Ward et al. 2001). Overall, differences were found between species in spatial dynamics and environmental cuing; however, overlaps were often observed implying potential for interspecific interactions. For example, Ward et al. (2001) suggested that mass mortalities of $S$. sagax may facilitate an expansion of E. australis because of highly overlapped species distributions and possible direct interactions. Barange et al. (2005) showed changes in overlaps of E. capensis and S. sagax with their biomass phases.

Spawning habitats of small pelagic fish species are presumably determined by environmental factors (van der Lingen et al. 2005) as well as population size and 
structure (Barange et al. 2005, Bellier et al. 2007). In particular, temperature-salinity diagrams have allowed the spawning habitats of anchovy and sardine to be discriminated in various ecosystems (Checkley et al. 2000, van der Lingen et al. 2005, Oozeki et al. 2007). Off the Pacific coast of Japan, the Kuroshio current meander impacts spawning habitats through its regulation of oceanographic conditions (Nakata et al. 2000). Japanese anchovy have broader spawning temperature optima, with the mid-point of the optima at $22^{\circ} \mathrm{C}$, while Japanese sardine have narrower temperature optima with a marked peak at $16^{\circ} \mathrm{C}$ (Takasuka et al. 2008a). Hence, Japanese anchovy is a warm, eurythermal species, while Japanese sardine is a cool, stenothermal species. These features are naturally reflected in their spawning seasons and peaks, which are partly responsible for the spawning overlaps. Biological characteristics of anchovy and sardine differ among ecosystems. For example, anchovy and sardine relationships are reversed in terms of spawning temperature optima between the opposite sides of the North Pacific (Takasuka et al. 2008b). Spawning seasons in association with temperature preferences lead to differences in extent of spawning overlaps. Therefore, comparison of spawning overlaps and other biological factors among ecosystems might be key to understanding the mechanisms of synchronous/asynchronous patterns of anchovy and sardine alternations.

Spawning overlap is a potential source of interspecific competition for spawners and offspring. In reality, the existence of competition can not be verified without further information on variables such as prey density, food consumption rates and relative competitive abilities between species. The relative impacts of intraspecific (Ward et al. 2006) and interspecific interactions among different life stages and trophic levels (Bakun 2006) should also be considered in elucidating the role of interactions. For example, intensive overlaps may cause larval predation (including cannibalism) on eggs and influence behavior and population dynamics of predators, leading to complexity in assessing interspecific interactions. However, we expect potential competition between anchovy and sardine based on circumstantial evidence. In general, Sardinops species are more adapted to filter-feeding; they have finer gill raker structures than Engraulis species. There is evidence showing differential feeding strategies during late-juvenile and adult stages (Tanaka 2006, van der Lingen et al. 2006). During early life stages, however, gut content compositions overlap considerably and gill raker morphologies are similar between Japanese anchovy and sardine captured in the same areas (Tanaka 2006). As such, competition would be probable in terms of overlapping niches and food items (Li et al. 1992, Yatsu et al. 2005).
Bakun \& Cury (1999) introduced the concept of 'school-trap' into the list of biological mechanisms explaining anchovy and sardine alternations, based on 2 assumptions. First, different small pelagic species tend to form mixed-species schools if they are similar in body size. Second, schooling is an adaptive strategy of anti-predator behavior so that individuals cannot be isolated from the schools. The 'school trap' hypothesis posits that the minor species in the mixed schools suffer from biological disadvantages of being minor per se because the schools tend to act to the advantage of the dominant species in migration, feeding and spawning. Despite such adverse circumstances, the minor species cannot leave the schools, and finally become less abundant. Although the 'school trap' theory is intended for adult school behaviors, the idea could be applied to the early life stages, since larvae also form shoals and in fact anchovy and sardine larvae are both sometimes included in the same commercial trawl catches (Nakata et al. 2000). Disadvantage for the minority was also implied in the 'odd species out' phenomena found in coral reef fish communities (Almany \& Webster 2004). By comparing recruits between predator-present and predator-removed reefs, Almany \& Webster (2004) demonstrated that rare species were consumed disproportionately more in multispecies prey communities. These mechanisms cannot explain the alternations from one species to the other as it implies the disappearance of a species that becomes less abundant. However, they would have explanatory power for certain phases such as a drastic population decrease or collapse of one species and an increase in the other.

The biological mechanisms of anchovy and sardine alternations are likely phase-specific. Spawning overlaps and subsequent interspecific interactions are not the dominant regulator of the alternations but could serve to promote alternations or depress recovery of the minor species once the shift of dominance occurs. In this context, Japanese sardine population recovery is considered to be more difficult than Japanese anchovy population recovery when interspecific interactions occur. This difference is attributable to spawning temperature optima and the conclusion may have generality among many stenothermal and eurythermal species. The present analysis suggests another possible pathway of the recent non-recovery of sardine other than fishing mortality, but it does not view intensive fishing with approval, since fishing impacts may be more critical under adverse conditions (Yatsu et al. 2005, Shelton et al. 2006). Rather, we propose that such differential biological attributes in multispecies assemblages should be incorporated into overall sustainable management of multi-species stocks. 
Acknowledgements. The present data set is a product of enormous efforts by many researchers, officers, crew and operators participating in the egg and larval surveys. In 2005 and 2006, the data set was updated with the help of S. Aono, M. Chiba, T. Chiyokubo, H. Ebina, H. Egami, H. Fukuda, O. Funaki, H. Hashimoto, K. Horikoshi, S. Inaba, T. Inai, M. Ishida, M. Kajiya, M. Kato, I. Kawamoto, N. Kikuya, K. Kobayashi, H. Kobinata, Y. Koizumi, M. Morinaga, S. Morioka, T. Nagaki, H. Nakategawa, K. Ninokata, K. Omote, M. Saito, Y. Sanada, K. Shiraishi, T. Suzuki, T. Suzuki, N. Takahashi, K. Tanaka, R. Utsumi, S. Yamada, H. Yamada and N. Yasumi. The manuscript benefited from discussions and communications with T. Akamine, M. Barange, T. Katsukawa, H. Okamura, H. Tanaka, N. Yamashita, M. Yoneda and the members of the NEMURO.SAN project, which is organized by S. Ito, M. Kishi, B. Megrey, K. Rose and F. Werner. The present study was partly supported by a Grant-in-Aid for Scientific Research from the Ministry of Education, Culture, Sports, Science and Technology, Japan.

\section{LITERATURE CITED}

Almany GR, Webster MS (2004) Odd species out as predators reduce diversity of coral-reef fishes. Ecology 85: 2933-2937

Bakun A (2006) Wasp-waist populations and marine ecosystem dynamics: navigating the 'predator pit' topographies. Prog Oceanogr 68:271-288

Bakun A, Cury P (1999) The "school trap": a mechanism promoting large-amplitude out-of-phase population oscillations of small pelagic fish species. Ecol Lett 2:349-351

Barange M, Hampton I (1997) Spatial structure of co-occurring anchovy and sardine populations from acoustic data: implications for survey design. Fish Oceanogr 6:94-108

Barange M, Coetzee JC, Twatwa NM (2005) Strategies of space occupation by anchovy and sardine in the southern Benguela: the role of stock size and intra-species competition. ICES J Mar Sci 62:645-654

Bellier E, Planque B, Petitgas P (2007) Historical fluctuations in spawning location of anchovy (Engraulis encrasicolus) and sardine (Sardina pilchardus) in the Bay of Biscay during 1967-73 and 2000-2004. Fish Oceanogr 16:1-15

Botsford LW, Castilla JC, Peterson CH (1997) The management of fisheries and marine ecosystems. Science 277 : 509-515

Chavez FP, Ryan J, Lluch-Cota SE, Niquen CM (2003) From anchovies to sardines and back: multidecadal change in the Pacific Ocean. Science 299:217-221

Checkley DM Jr, Dotson RC, Griffith DA (2000) Continuous, underway sampling of eggs of Pacific sardine (Sardinops sagax) and northern anchovy (Engraulis mordax) in spring 1996 and 1997 off southern and central California. DeepSea Res II 47:1139-1155

Curtis KA (2004) Fine scale spatial pattern of Pacific sardine (Sardinops sagax) and northern anchovy (Engraulis mordax) eggs. Fish Oceanogr 13:239-254

Giannoulaki M, Machias A, Koutsikopoulos C, Somarakis S (2006) The effect of coastal topography on the spatial structure of anchovy and sardine. ICES J Mar Sci 63: $650-662$

> Gutiérrez M, Swartzman G, Bertrand A, Bertrand S (2007) Anchovy (Engraulis ringens) and sardine (Sardinops sagax) spatial dynamics and aggregation patterns in the Humboldt Current ecosystem, Peru, from 1983-2003. Fish Oceanogr 16:155-168

Hattori M (1983) Relationship of developmental rate of Japan- ese anchovy eggs with temperature. Report of the 15th meeting of Nansei Regional Block Inland Sea Fisheries Research, Nansei Regional Fisheries Research Laboratory, Hiroshima, p 59-64 (in Japanese)

Katsukawa T (2007) Fisheries impact on Japanese sardine. Nippon Suisan Gakkai Shi 73:763-766 (in Japanese)

> Lehodey P, Alheit J, Barange M, Baumgartner T and others (2006) Climate variability, fish, and fisheries. J Clim 19: 5009-5030

Li XY, Kawasaki T, Honda H (1992) The niches of the Far Eastern sardine and Japanese anchovy. Asian Fish Sci 5: 315-326

Lluch-Belda D, Crawford RJM, Kawasaki T, MacCall AD, Parrish RH, Schwartzlose RA, Smith PE (1989) World-wide fluctuations of sardine and anchovy stocks: the regime problem. S Afr J Mar Sci 8:195-205

Lluch-Belda D, Lluch-Cota DB, Hernandez-Vazquez S, Salinas-Zavala CA, Schwartzlose RA (1991) Sardine and anchovy spawning as related to temperature and upwelling in the California Current system. Calif Coop Ocean Fish Investig Rep 32:105-111

Mori K, Kuroda K, Konishi Y (eds) (1988) Monthly egg productions of the Japanese sardine, anchovy, and mackerels off the southern coast of Japan by egg censuses: January, 1978 through December, 1986. Tokai Regional Fisheries Research Laboratory, Tokyo (in Japanese)

Nakai Z, Hattori S (1962) Quantitative distribution of eggs and larvae of the Japanese sardine by year, 1949 through 1951. Bull Tokai Reg Fish Res Lab 9:23-60

Nakata H, Funakoshi S, Nakamura M (2000) Alternating dominance of postlarval sardine and anchovy caught by coastal fishery in relation to the Kuroshio meander in the Enshu-nada Sea. Fish Oceanogr 9:248-258

Nishida H, Yatsu A, Ishida M, Noto M, Katsukawa Y (2005) Stock assessment and evaluation for the Pacific stock of Japanese sardine (fiscal year 2005). In: Marine fisheries stock assessment and evaluation for Japanese waters (fiscal year 2005/2006), Fisheries Agency and Fisheries Research Agency of Japan, Fisheries Agency, Tokyo and Fisheries Research Agency, Yokohama, p 11-45 (in Japanese)

Oozeki Y, Kubota H, Takasuka A, Akamine T, Shimizu A (2005) Stock assessment and evaluation for the Pacific stock of Japanese anchovy (fiscal year 2005). In: Marine fisheries stock assessment and evaluation for Japanese waters (fiscal year 2005/2006), Fisheries Agency and Fisheries Research Agency of Japan, p 604-628 (in Japanese)

Oozeki Y, Takasuka A, Kubota H, Barange M (2007) Characterizing spawning habitats of Japanese sardine (Sardinops melanostictus), Japanese anchovy (Engraulis japonicus), and Pacific round herring (Etrumeus teres) in the northwestern Pacific. Calif Coop Ocean Fish Investig Rep 48: 191-203

> Planque B, Bellier E, Lazure P (2007) Modelling potential spawning habitat of sardine (Sardina pilchardus) and anchovy (Engraulis encrasicolus) in the Bay of Biscay. Fish Oceanogr 16:16-30

Rodríguez-Sánchez R, Lluch-Belda D, Villalobos H, OrtegaGarcía S (2002) Dynamic geography of small pelagic fish populations in the California Current System on the regime time scale (1931-1997). Can J Fish Aquat Sci 59: 1980-1988

Schwartzlose RA, Alheit J, Bakun A, Baumgartner TR and others (1999) Worldwide large-scale fluctuations of sardine and anchovy populations. S Afr J Mar Sci 21:289-347

> Shelton PA, Sinclair AF, Chouinard GA, Mohn R, Duplisea DE (2006) Fishing under low productivity conditions is further 
delaying recovery of Northwest Atlantic cod (Gadus morhua). Can J Fish Aquat Sci 63:235-238

Smith PE, Horne JK, Schneider DC (2001) Spatial dynamics of anchovy, sardine, and hake pre-recruit stages in the California Current. ICES J Mar Sci 58:1063-1071

Takasuka A, Aoki I (2006) Environmental determinants of growth rates for larval Japanese anchovy Engraulis japonicus in different waters. Fish Oceanogr 15:139-149

Takasuka A, Oozeki Y, Aoki I (2007) Optimal growth temperature hypothesis: Why do anchovy flourish and sardine collapse or vice versa under the same ocean regime? Can J Fish Aquat Sci 64:768-776

'Takasuka A, Oozeki Y, Kubota H (2008a) Multi-species regime shifts reflected in spawning temperature optima of small pelagic fish in the western North Pacific. Mar Ecol Prog Ser 360:211-217

Takasuka A, Oozeki Y, Kubota H, Lluch-Cota SE (2008b) Contrasting spawning temperature optima: Why are anchovy and sardine regime shifts synchronous across the North Pacific? Prog Oceanogr 77:225-232

Tanaka H (2006) Comparative study of the feeding ecology of small pelagic fish with a focus on Japanese anchovy Engraulis japonicus. PhD thesis, University of Tokyo, Tokyo

Twatwa NM, van der Lingen CD, Drapeau L, Moloney CL, Field JG (2005) Characterising and comparing the spawning habitats of anchovy Engraulis encrasicolus and sardine Sardinops sagax in the southern Benguela upwelling ecosystem. Afr J Mar Sci 27:487-499

van der Lingen CD, Castro L, Drapeau L, Checkley D Jr. (ed) (2005) Report of a GLOBEC-SPACC workshop on characterizing and comparing the spawning habitats of small pelagic fish. GLOBEC Report 21, GLOBEC International Project Office, Plymouth

Editorial responsibility: Matthias Seaman, Oldendorf/Luhe, Germany van der Lingen CD, Hutchings L, Field JG (2006) Comparative trophodynamics of anchovy Engraulis encrasicolus and sardine Sardinops sagax in the southern Benguela: Are species alternations between small pelagic fish trophodynamically mediated? Afr J Mar Sci 28:465-477

Ward TM, Hoedt F, McLeay L, Dimmlich WF, Jackson G, Rogers PJ, Jones K (2001) Have recent mass mortalities of the sardine Sardinops sagax facilitated an expansion in the distribution and abundance of the anchovy Engraulis australis in South Australia? Mar Ecol Prog Ser 220: 241-251

Ward AJW, Webster MM, Hart PJB (2006) Intraspecific food competition in fishes. Fish Fish 7:231-261

Watanabe T (1983) Spawning survey method. In: Ishii T (ed) Population dynamics of fishery resources. Koseisha Koseikaku, Tokyo, p 9-29 (in Japanese)

Watanabe Y, Zenitani H, Kimura R (1996) Offshore expansion of spawning of the Japanese sardine, Sardinops melanostictus, and its implication for egg and larval survival. Can J Fish Aquat Sci 53:55-61

Watanabe Y, Zenitani H, Kimura R (1997) Variations in spawning ground area and egg density of the Japanese sardine in Pacific coastal and oceanic waters. Fish Oceanogr 6:35-40

Yatsu A, Watanabe T, Ishida M, Sugisaki H, Jacobson LD (2005) Environmental effects on recruitment and productivity of Japanese sardine Sardinops melanostictus and chub mackerel Scomber japonicus with recommendations for management. Fish Oceanogr 14:263-278

Zenitani H, Kimura R (1997) Increase in late winter egg production of the Japanese anchovy as related to recovery of the stock size along the Pacific coast of Japan. Nippon Suisan Gakkai Shi 63:665-671 (in Japanese with English abstract)

Submitted: April 11, 2007; Accepted: April 7, 2008

Proofs received from author(s): August 20, 2008 